\title{
The role of calcium, lipid membranes and islet amyloid polypeptide in the onset of type 2 diabetes: innocent bystanders or partners in a crime?
}

\author{
Danilo Milardi ${ }^{1}$, Michele F. M. Sciacca ${ }^{2}$, Loredana Randazzo ${ }^{1}$, Antonino Raudino ${ }^{2}$ and Carmelo La Rosa ${ }^{2}$ * \\ Istituto CNR di Biostrutture e Bioimmagini-Sezione di Catania, Catania, Italy \\ ${ }^{2}$ Dipartimento di Scienze Chimiche Viale Andrea Doria 6, Università Degli Studi di Catania, Catania, Italy \\ *Correspondence: clarosa@unict.it \\ Edited by: \\ Low-Tone Ho, Taipei Veterans General Hospital, Taiwan \\ Reviewed by: \\ Kerry Loomes, University of Auckland, New Zealand
}

Keywords: type II diabetes mellitus, amyloid, membranes, calcium, obesity, free fatty acids, genetic predisposition

\section{INTRODUCTION}

Type II diabetes mellitus (T2DM) is one of the most disabling age-related pathologies in developed countries (1). Its incidence is constantly growing: the number of people affected by T2DM worldwide grew from 28 million cases in 1985 to around 168 million in 2001, with an estimate of 350 million cases in 2030 (2).

Despite the intense research efforts focusing on T2DM in the last 20 years, the cause of the underlying pathology is still unclear. Islet Amyloid Polypeptide (IAPP) is an amyloidogenic protein, member of the calcitonin family (3), which is known to be involved in the mechanisms lying at the root of T2DM pathogenesis $(4,5)$. Indeed, although the correlation between islet $\beta$ cell death and amyloid fibril formation is still a matter of debate, recent studies, performed on transgenic mice, show that IAPP aggregation can mediate $\beta$-cell failure in T2DM (6). Indeed, despite human and rat variants of IAPP differing by only six amino acids, the two variants behave in a completely different way. In particular, rat IAPP (rIAPP) is unable to form amyloid aggregates under normal conditions (7) and rats do not develop T2DM in analogous conditions. Human IAPP (hIAPP) amyloid aggregates are detectable in pancreas' extracellular space in $90 \%$ of patients (4), while only $10 \%$ of patients do not have detectable amyloid deposits.

We propose that T2DM etiology might be clarified by studying the close relationships between three apparently independent issues: (i) amyloid toxicity; (ii) genetic factors; and (iii) environmental risk factors related to lifestyle and diet.

\section{MECHANISMS OF IAPP-INDUCED MEMBRANE DISRUPTION}

The mechanisms by which amyloid intermediates (A $\beta$ peptide, hIAPP, and other amyloid-forming proteins) cause cytotoxicity and disease remains unsolved, although some recent studies (8) suggest that the water/membrane interface is critical for influencing amyloid aggregation. Of note, mature amyloid fibrils are presumed to be inert while small oligomeric intermediates are suggested to penetrate the cell membrane (9). It has been hypothesized that amyloid-forming peptides may cause membrane damage by: (a) changing the bilayer fluidity, (b) generating proteinstabilized pores (poration), (c) laying on one leaflet of the membrane (carpeting), or (d) removing lipid components from the bilayer by detergent-like mechanisms (10). It has also been shown that the formation of amyloid fibers occurs independently of membrane leakage and that membrane composition and the presence of ions may have a major influence on amyloidmediated membrane damage (11).

In recent years, several studies have focused on the interpretation of molecular mechanisms underlying T2DM. In particular, researchers investigated the interaction between hIAPP and phospholipid membranes, a process that seems to be correlated to the loss of pancreatic $\beta$-cells (12-15). The most recent results suggest that hIAPP-induced membrane disruption could be described as a two independent step process. The first step is correlated with pore formation occurring after the insertion of monomeric or oligomeric species inside the membrane hydrophobic core.
The insertion of a protein into a membrane interferes with lipid packing and, at high concentration, it might result in a local bending deformation. To minimize the energetically unfavorable deformation, proteins tend to cluster (16). The second step of membrane disruption is correlated with the growth of fibers onto the membrane surface, which causes complete membrane dissolution through a detergent-like mechanism $(13,17)$.

Since the two steps are independent processes, they might be separately targeted by novel therapeutic approaches. The membrane lipid composition has been shown to be a critical point for the mechanism of membrane disruption mediated by hIAPP. The presence of phosphatidylethanolamine headgroup lipids, for example, can modulate the entity of the first and second step of membrane disruption. Also, the presence of cholesterol could finely regulate membrane dissolution by both inhibiting the affinity of hIAPP for the membrane as well as its insertion in the bilayer. Unfortunately, to date there are a lack of studies that have systematically investigated the role played by membrane composition (i.e., length of hydrophobic tails, percentage of cholesterol, presence of different lipid headgroups) on hIAPP/membrane interactions.

Therefore, the membrane disruption mechanism can be regulated by several factors, such as metal ions balance, increased hIAPP secretion, the presence of free fatty acid, etc. which could arise from genetic predisposition, lifestyle, and diet. 


\section{GENETIC RISK FACTORS IN THE DEVELOPMENT OF T2DM: INSULIN AND CALCIUM RECEPTORS}

Despite enormous efforts, the precise identification of the genetic determinants responsible for T2DM still remains unsolved. T2DM is not considered a genetic disease. Although recent papers demonstrate that the S20G mutation in the primary structure of hIAPP leads to an early variant of T2DM $(18,19)$, the incidence of this variant is very small compared to the number of patients affected by T2DM that do not show mutations in the hIAPP sequence. Moreover, studies focusing on the search for genetic factors involved in insulin resistance were inconclusive. For instance, defects on insulin receptors (INSR), correlated with insulin resistance, have been associated with T2DM, but only $3-4 \%$ of these patients show mutations of INSR genes (20). Other genes involved in triggering insulin resistance have been discovered: glucokinase regulatory protein (GKRP) (21), and insulin-like growth factor-I (IGFI) (22). It has been reported that calpain-10 and later transcription factor 7-like two genes in affected individuals increase the risk to develop T2DM (23).

Recently, genetic factors involved in calcium dyshomeostasis have attracted much attention of scientists. It was noted that patients affected by familial hypercalciuric hypercalcemia, a genetic disease related to a reduction of calcium receptor gene expression, are much more prone to developing T2DM (24). This evidence supports a key role played by genetic factors regulating calcium dyshomeostasis in the development of T2DM. It is tempting to suggest that high plasma $\mathrm{Ca}^{2+}$ levels may activate pathogenic molecular mechanisms involving hIAPP-mediated membrane disruption, as already reported in literature $(11,25)$. It has been reported that there is an increase in the intracellular calcium ion concentration $\left(\left[\mathrm{Ca}^{2+}\right]_{\mathrm{i}}\right)$ in diabetic subjects $(26,27)$. Notably, dysregulation of $\left[\mathrm{Ca}^{2+}\right]_{\mathrm{i}}$ in the cells of several tissues spontaneously occurs during aging as well as in obese people (28-30). Dyshomeostasis of intracellular $\mathrm{Ca}^{2+}$ can affect several membrane-related functions, such as domain organization, vesicular trafficking, and membrane adhesion/fusion $(31,32)$. A correlation between $\mathrm{Ca}^{2+}$ dyshomeostasis and hIAPP-membrane interaction $(11,25)$ has also been shown. In particular, it was observed that an increase of $\mathrm{Ca}^{2+}$ concentration facilitates hIAPP penetration into the phospholipid membrane to form pores (11).

\section{WEIGHT GAIN AND T2DM: THE ROLE OF FREE FATTY ACIDS}

Several lifestyle factors, which characterize the most developed countries, affect the incidence of T2DM $(33,34)$. For example obesity or, more generally, weight gain, significantly increase the risk of developing the disease (35-37). Other risk factors are physical inactivity (35), habitual energy intake in relation to expenditure (35), composition of the diet $(38,39)$, and metabolic characteristics (35).

Insulin resistance, which is actually considered the starting point for the development of T2DM, is strictly correlated with weight gain $(40,41)$. From a molecular point of view, obesity leads to calcium dyshomeostasis (30), increased concentration of free fatty acids (FFA) (42), and cholesterol $(43,44)$. All of these effects have been shown to be involved in the molecular mechanisms leading to hIAPP-induced disruption of Langerhans' $\beta$-cells $(11,25,45$, 46). Thus, these metabolic effects could all represent a common link between environmental factors and molecular mechanisms.

Plasma FFA concentration is usually elevated in obesity. It is worth noting that FFA may have a deep influence on $\mathrm{Ca}^{2+}$ homeostasis, which in turn triggers lipotoxic pathways leading to T2DM (47). Also, it has been shown that elevated FFA can cause insulin resistance and thus represents a common link between obesity, insulin resistance, and the development of T2DM. Elevation of plasma FFA levels in obesity is contributed by increased FFA release from enlarged adipose tissue, and reduced FFA clearance (48). Insulin resistance induced by high levels of FFA results in hyperinsulinemia and increased secretion of hIAPP. In turn, an increase in the local concentration of hIAPP mediates a more efficient interaction with the membrane resulting in pore formation and fibril elongation on the membrane surface (13). This conclusion is in agreement with previous studies demonstrating that high FFA concentrations enhance hIAPP fibrillogenicity (49).
To overcome the poor availability of isolated human islets, hIAPP-expressing transgenic mice were recently employed to investigate the role of high-fat diet on hIAPP amyloidosis. However, it is worth noting that amyloid growth in hIAPPexpressing transgenic mice and in human islets may significantly differ (50) since in human islets the amyloid aggregation starts intracellularly, while in transgenic mice amyloid growth is predominantly extracellular. It is important to point out that the diverse observations regarding whether hIAPP aggregation occurs intraceullarly or extraceullarly may likely depend on differing in vivo metabolic environments. It is tempting to speculate that differences in membrane lipid composition of rodents and human beings may play a major role in differentiating hIAPP behavior (51).

\section{FUTURE PERSPECTIVES}

T2DM is a pathology in which several factors are tightly interconnected. Mounting evidence points to a relationship between hIAPP amyloid, calcium dysregulation, membrane damage, and $\beta$-cell death. To date, inhibition of IAPP amyloid growth has been a matter of major interest. Overall, researcher efforts focusing on the design of molecules targeting hIAPP amyloid have been useful in providing different classes of anti-T2DM candidates $(6,52)$, however, to date, none of these compounds have been selected for clinical trials. Nowadays, the increasing knowledge of the mechanism of hIAPP toxicity moves the focus toward the development of molecules that can halt amyloid-mediated membrane damage. Since a two steps mechanism for membrane disruption mediated by hIAPP has been proposed, an efficient drug should inhibit both poration and fiber formation on membrane surface. However, there is still a lack of knowledge about the cross correlation of genetic, lifestyle and diet effects.

The use of model membranes allows researchers to study a simpler system than cells and to isolate single parameters affecting the process. An oversimplification in terms of lipid composition could lead, however, to misleading results. In order to fit in vitro and in vivo experiments with the process occurring in people affected by T2DM, future cell-free experiments should thus take into account the effects 
of genetic factors, lifestyle and diet. In particular, the effect of: (i) membrane composition, (ii) calcium ions, and (iii) FFA should be addressed by biophysical methods including Thioflavine $\mathrm{T}$ (ThT) fluorescence assays, dye-leakage, solid state NMR experiments, and large scale molecular simulations with the aim of providing a molecular description of the cascade of pathogenic events occurring upon hIAPP aggregation at water/lipid interfaces. Hopefully, these studies will help to effectively design and screen an increasingly large number of new compounds able to inhibit hIAPP aggregation also in the presence of lipid interfaces mimicking cell membranes and, in turn, to better manage IAPP toxicity in humans.

\section{ACKNOWLEDGMENTS}

We acknowledge University of Catania and PRIN 2010/2011, Cod. prog.: 2010L96H3K for financial support.

\section{REFERENCES}

1. Chen L, Magliano DJ, Zimmet PZ. The worldwide epidemiology of type 2 diabetes mellitus - present and future perspectives. Nat Rev Endocrinol (2012) 8:228-36. doi:10.1038/nrendo.2011.183

2. Shaw JE, Sicree RA, Zimmet PZ. Global estimates of the prevalence of diabetes for 2010 and 2030 . Diabetes Res Clin Pract (2010) 87:4-14. doi:10. 1016/j.diabres.2009.10.007

3. Wimalawansa SJ. Amylin, calcitonin gene-related peptide, calcitonin, and adrenomedullin: a peptide superfamily. Crit Rev Neurobiol (1997) 11:167-239. doi:10.1615/CritRevNeurobiol.v11.i2-3.40

4. Höppener JWM, Ahrén B, Lips CJM. Islet amyloid and type 2 diabetes mellitus. N Engl J Med (2000) 343:411-9. doi:10.1056/NEJM200008103430607

5. Hull RL, Westermark GT, Westermark P, Kahn SE. Islet amyloid: a critical entity in the pathogenesis of type 2 diabetes. J Clin Endocrinol Metab (2004) 89:3629-43. doi:10.1210/jc.2004-0405

6. Aitken JF, Loomes KM, Scott DW, Reddy S, Phillips ARJ, Prijic G, et al. Tetracycline treatment retards the onset and slows the progression of diabetes in human amylin/islet amyloid polypeptide transgenic mice. Diabetes (2010) 59:161-71. doi:10. 2337/db09-0548

7. Knight JD, Hebda JA, Miranker AD. Conserved and cooperative assembly of membrane-bound alpha-helical states of islet amyloid polypeptide. Biochemistry (Mosc) (2006) 45:9496-508. doi:10. 1021/bi060579z

8. Zhang Y, Luo Y, Deng Y, Mu Y, Wei G. Lipid interaction and membrane perturbation of human islet amyloid polypeptide monomer and dimer by molecular dynamics simulations. PLoS One (2012) 7:e38191. doi:10.1371/journal.pone.0038191

9. Anguiano M, Nowak RJ, Lansbury PT. Protofibrillar islet amyloid polypeptide permeabilizes synthetic vesicles by a pore-like mechanism that may be relevant to type II diabetes. Biochemistry (Mosc) (2002) 41:11338-43. doi:10.1021/bi020314u

10. Hebda JA, Miranker AD. The interplay of catalysis and toxicity by amyloid intermediates on lipid bilayers: insights from type II diabetes. Annu Rev Biophys (2009) 38:125-52. doi:10.1146/annurev. biophys.050708.133622

11. Sciacca MFM, Milardi D, Messina GML, Marletta G, Brender JR, Ramamoorthy A, et al. Cations as switches of amyloid-mediated membrane disruption mechanisms: calcium and IAPP. Biophys J (2013) 104:173-84. doi:10.1016/j.bpj.2012. 11.3811

12. Zhao J, Hu R, Sciacca MFM, Brender JR, Chen $\mathrm{H}$, Ramamoorthy A, et al. Non-selective ion channel activity of polymorphic human islet amyloid polypeptide (amylin) double channels. Phys Chem Chem Phys (2014) 16:2368-77. doi:10.1039/ c3cp53345j

13. Sciacca MFM, Brender JR, Lee D-K, Ramamoorthy A. Phosphatidylethanolamine enhances amyloid fiber-dependent membrane fragmentation. Biochemistry (Mosc) (2012) 51:7676-84. doi:10.1021/ bi3009888

14. Scalisi S, Sciacca MFM, Zhavnerko G, Grasso DM, Marletta G, La Rosa C. Self-assembling pathway of HiApp fibrils within lipid bilayers. Chembiochemistry (2010) 11:1856-9. doi:10.1002/cbic. 201000090

15. Milardi D, Sciacca MFM, Pappalardo M, Grasso DM, Rosa CL. The role of aromatic side-chains in amyloid growth and membrane interaction of the islet amyloid polypeptide fragment LANFLVH. Eur Biophys J (2011) 40:1-12. doi:10.1007/s00249010-0623-x

16. Pannuzzo M, Milardi D, Raudino A, Karttunen M, La Rosa C. Analytical model and multiscale simulations of $\mathrm{A} \beta$ peptide aggregation in lipid membranes: towards a unifying description of conformational transitions, oligomerization and membrane damage. Phys Chem Chem Phys PCCP (2013) 15:8940-51. doi:10.1039/c3cp44539a

17. Sciacca MFM, Kotler SA, Brender JR, Chen J, Lee D, Ramamoorthy A. Two-step mechanism of membrane disruption by $A \beta$ through membrane fragmentation and pore formation. Biophys J (2012) 103:702-10. doi:10.1016/j.bpj.2012.06.045

18. Sakagashira S, Sanke T, Hanabusa T, Shimomura H, Ohagi S, Kumagaye KY, et al. Missense mutation of amylin gene (S20G) in Japanese NIDDM patients. Diabetes (1996) 45:1279-81. doi:10.2337/ diab.45.9.1279

19. Hiddinga HJ, Sakagashira S, Ishigame M, Madde P, Sanke T, Nanjo K, et al. Expression of wild-type and mutant S20G hIAPP in physiologic knock-in mouse models fails to induce islet amyloid formation, but induces mild glucose intolerance. J Diabetes Investig (2012) 3:138-47. doi:10.1111/j.20401124.2011.00166.x

20. Ahlqvist E, Ahluwalia TS, Groop L. Genetics of type 2 diabetes. Clin Chem (2011) 57:241-54. doi:10.1373/clinchem.2010.157016

21. Choi JM, Seo M-H, Kyeong H-H, Kim E, Kim H-S. Molecular basis for the role of glucokinase regulatory protein as the allosteric switch for glucokinase. Proc Natl Acad Sci US A (2013) 110:10171-6. doi:10.1073/pnas.1300457110

22. Beardsall K, Vanhaesebrouck S, Frystyk J, Ogilvy-Stuart AL, Vanhole C, van Weissenbruch
$\mathrm{M}$, et al. Relationship between insulin-like growth factor I levels, early insulin treatment, and clinical outcomes of very low birth weight infants. JPediatr (2014) 164:1038.e-44.e. doi:10.1016/j.jpeds.2013. 12.046

23. Horikawa Y, Oda N, Cox NJ, Li X, Orho-Melander M, Hara $M$, et al. Genetic variation in the gene encoding calpain-10 is associated with type 2 diabetes mellitus. Nat Genet (2000) 26:163-75. doi:10.1038/79876

24. Chattopadhyay N, Brown EM. Calcium-Sensing Receptor. Springer Science \& Business Media (2003).

25. Sciacca MFM, Pappalardo M, Milardi D, Grasso DM, Rosa CL. Calcium-activated membrane interaction of the islet amyloid polypeptide: implications in the pathogenesis of type II diabetes mellitus. Arch Biochem Biophys (2008) 477:291-8. doi:10.1016/j.abb.2008.06.018

26. Resnick LM. Cellular calcium and magnesium metabolism in the pathophysiology and treatment of hypertension and related metabolic disorders. Am J Med (1992) 93:11S-20S. doi:10.1016/00029343(92)90290-R

27. Barbagallo M, Gupta RK, Resnick LM. Cellular ions in NIDDM: relation of calcium to hyperglycemia and cardiac mass. Diabetes Care (1996) 19:1393-8. doi:10.2337/diacare.19.12.1393

28. Squier TC, Bigelow DJ. Protein oxidation and age-dependent alterations in calcium homeostasis. Front Biosci J Virtual Libr (2000) 5:D504-26. doi:10.2741/Squier

29. Nitahara JA, Cheng W, Liu Y, Li B, Leri A, Li $\mathrm{P}$, et al. Intracellular calcium, DNase activity and myocyte apoptosis in aging Fischer 344 rats. $J \mathrm{Mol}$ Cell Cardiol (1998) 30:519-35. doi:10.1006/jmcc. 1997.0616

30. Astrup A. The role of calcium in energy balance and obesity: the search for mechanisms. Am J Clin Nutr (2008) 88:873-4.

31. Rescher U, Gerke V. Annexins - unique membrane binding proteins with diverse functions. J Cell Sci (2004) 117:2631-9. doi:10.1242/jcs.01245

32. Gerke V, Creutz CE, Moss SE. Annexins: linking $\mathrm{Ca} 2+$ signalling to membrane dynamics. Nat Rev Mol Cell Biol (2005) 6:449-61. doi:10.1038/ nrm 1661

33. Kuczmarski RJ, Flegal KM, Campbell SM, Johnson CL. Increasing prevalence of overweight among US adults. The National Health and Nutrition Examination Surveys, 1960 to 1991. JAMA J Am Med Assoc (1994) 272:205-11. doi:10.1001/jama. 272.3.205

34. Meier DT, Morcos M, Samarasekera T, Zraika S, Hull RL, Kahn SE. Islet amyloid formation is an important determinant for inducing islet inflammation in high-fat-fed human IAPP transgenic mice. Diabetologia (2014) 57:1884-8. doi:10.1007/ s00125-014-3304-y

35. Steyn NP, Mann J, Bennett PH, Temple N, Zimmet P, Tuomilehto J, et al. Diet, nutrition and the prevention of type 2 diabetes. Public Health Nutr (2004) 7:147-65. doi:10.1079/PHN2003586

36. Knowler WC, Pettitt DJ, Savage PJ, Bennett PH. Diabetes incidence in Pima indians: contributions of obesity and parental diabetes. Am J Epidemiol (1981) 113:144-56.

37. Kahn SE, Hull RL, Utzschneider KM. Mechanisms linking obesity to insulin resistance and type 2 
diabetes. Nature (2006) 444:840-6. doi:10.1038/ nature 05482

38. Swinburn BA, Metcalf PA, Ley SJ. Long-term (5year) effects of a reduced-fat diet intervention in individuals with glucose intolerance. Diabetes Care (2001) 24:619-24. doi:10.2337/diacare.24.4.619

39. Astrup A, Grunwald GK, Melanson EL, Saris $\mathrm{WH}$, Hill JO. The role of low-fat diets in body weight control: a meta-analysis of ad libitum dietary intervention studies. Int $J$ Obes Relat Metab Disord (2000) 24:1545-52. doi:10.1038/sj. ijo.0801453

40. Boden G. Role of fatty acids in the pathogenesis of insulin resistance and NIDDM. Diabetes (1997) 46:3-10. doi:10.2337/diab.46.1.3

41. Boden G, Chen X, Ruiz J, White JV, Rossetti L. Mechanisms of fatty acid-induced inhibition of glucose uptake. J Clin Invest (1994) 93:2438-46. doi:10.1172/JCI117252

42. Reaven GM, Hollenbeck C, Jeng CY, Wu MS, Chen YD. Measurement of plasma glucose, free fatty acid, lactate, and insulin for $24 \mathrm{~h}$ in patients with NIDDM. Diabetes (1988) 37:1020-4. doi:10.2337/ diabetes.37.8.1020

43. Tanner JM. The relation between serum cholesterol and physique in healthy young men. J Physiol (1951) 115:371-90.

44. Montoye HJ, Epstein FH, Kjelsberg MO. Relationship between serum cholesterol and body fatness. An epidemiologic study. Am J Clin Nutr (1966) 18:397-406.
45. Sasahara K, Morigaki K, Shinya K. Amyloid aggregation and deposition of human islet amyloid polypeptide at membrane interfaces. FEBS $J$ (2014) 281:2597-612. doi:10.1111/febs.12807

46. Wakabayashi M, Matsuzaki K. Gangliosideinduced amyloid formation by human islet amyloid polypeptide in lipid rafts. FEBS Lett (2009) 583:2854-8. doi:10.1016/j.febslet.2009.07.044

47. Yang H, Li X. The role of fatty acid metabolism and lipotoxicity in pancreatic $\beta$-cell injury: identification of potential therapeutic targets. Acta Pharm Sin B (2012) 2:396-402. doi:10.1016/j.apsb.2012. 05.003

48. Björntorp P, Bergman H, Varnauskas E. Plasma free fatty acid turnover rate in obesity. Acta Med Scand (1969) 185:351-6. doi:10.1111/j.0954-6820.1969. tb07347.x

49. Ma Z, Westermark GT. Effects of free fatty acid on polymerization of islet amyloid polypeptide (IAPP) in vitro and on amyloid fibril formation in cultivated isolated islets of transgenic mice overexpressing human IAPP. Mol Med (2002) 8:863-8.

50. Westermark P, Andersson A, Westermark GT. Islet amyloid polypeptide, islet amyloid, and diabetes mellitus. Physiol Rev (2011) 91:795-826. doi:10. 1152/physrev.00042.2009

51. MacDonald MJ, Dobrzyn A, Ntambi J, Stoker SW. The role of rapid lipogenesis in insulin secretion: insulin secretagogues acutely alter lipid composition of INS-1 832/13 cells. Arch Biochem
Biophys (2008) 470:153-62. doi:10.1016/j.abb. 2007.11.017

52. Stefani M, Rigacci S. Protein folding and aggregation into amyloid: the interference by natural phenolic compounds. Int J Mol Sci (2013) 14:12411-57. doi:10.3390/ijms140612411

Conflict of Interest Statement: The authors declare that the research was conducted in the absence of any commercial or financial relationships that could be construed as a potential conflict of interest.

Received: 25 July 2014; accepted: 01 December 2014; published online: 17 December 2014

Citation: Milardi D, Sciacca MFM, Randazzo L, Raudino $A$ and La Rosa C (2014) The role of calcium, lipid membranes and islet amyloid polypeptide in the onset of type 2 diabetes: innocent bystanders or partners in a crime? Front. Endocrinol. 5:216. doi: 10.3389/fendo.2014.00216

This article was submitted to Diabetes, a section of the journal Frontiers in Endocrinology.

Copyright (c) 2014 Milardi, Sciacca, Randazzo, Raudino and La Rosa. This is an open-access article distributed under the terms of the Creative Commons Attribution License (CC BY). The use, distribution or reproduction in other forums is permitted, provided the original author(s) or licensor are credited and that the original publication in this journal is cited, in accordance with accepted academic practice. No use, distribution or reproduction is permitted which does not comply with these terms. 